\title{
CORRECTION
}

\section{Correction to: Anticoagulant Rodenticides and Raptors: Recent Findings from New York, 1998-2001}

\author{
W. B. Stone ${ }^{1}$ - J. C. Okoniewski ${ }^{1}$ - J. R. Stedelin ${ }^{2}$
}

Published online: 9 May 2020

(c) Springer Science+Business Media, LLC, part of Springer Nature 2020

\section{Correction to: \\ Bulletin of Environmental Contamination and Toxicology https://doi.org/10.1007/s00128-002-0152-0}

In the original version of this article, there is a typographical error in the third sentence of the Results and Discussion section. The number of cases in which anticoagulant-facilitated hemorrhage was considered the cause of death was 19 (not 9). This has been corrected with this erratum.

Publisher's Note Springer Nature remains neutral with regard to jurisdictional claims in published maps and institutional affiliations.

Correspondence to: W. B. Stone

The original article can be found online at https://doi.org/10.1007/ s00128-002-0152-0.

J. C. Okoniewski

joseph.okoniewski@dec.ny.gov

1 Wildlife Pathology Unit, New York State Department of Environmental Conservation, 108 Game Farm Road, Delmar, NY 12054, USA

2 Animal Disease Laboratory, Illinois Department of Agriculture, 9732 Shattuc Road, Centralia, IL 62801, USA 